\title{
MINIMIZING THE SHORT CIRCUIT CURRENT AND OVER- VOLTAGE IN A POWER DISTRIBUTION SYSTEM BY USING SFCL IN THE PRESENCE OF DISTRIBUTED GENERATION
}

\author{
P. Umapathi Reddy ${ }^{1}$, M. Anand Kumar ${ }^{2}$ \\ ${ }^{1}$ Professor, EEE, Sree Vidyanikethan Engineering College, Andhra Pradesh, India \\ ${ }^{2} M$. Tech Student, EPS, Sree Vidyanikethan Engineering College, Andhra Pradesh, India
}

\begin{abstract}
The insertion of distributed generation systems into power distribution system raises the fault current and over-voltage magnitude under fault condition. Application of SFCL will helps to avoid the situation. SFCL is the combination of air-core type transformer and pulse width modulation inverter. By regulating converter output current, the mmf in air-core transformer is changed to produce high SFCL equivalent impedance during abnormal condition. This will limit short circuit current magnitude. In this paper the effect of SFCL can be analyzed using simulation model and mathematical derivation. The performance of the SFCL on short circuit current and over-voltage magnitude limiting characteristics can be analyzed when distributed generators are connected at different locations. The short circuit current and overvoltage limiting characteristics of SFCL is simulated in MATLAB software. The results from simulation model shows that SFCL plays an important role in minimizing the over-voltage magnitude and short circuit currents during abnormal conditions.
\end{abstract}

Keywords: SFCL, Fault Detection, and PWM.

\section{INTRODUCTION}

Now a days to increase reliability of supply the power system network is interconnected and Distribution Generation is added, with this the network structure of power system becomes complex, the levels of short circuit current reached a new high value which may exceed the ratings of circuit breaker. With this increased current the circuit breakers may damage. So replacing the circuit breakers with high rating circuit breakers is not economical. Fault current limiters are used to limit the short circuit current and with FCL existing circuit breakers can handle the situation.

The features of an ideal FCL are shown below,

- Power losses are zero during normal operation.

- It shows zero impedance during normal condition.

- It should show high impedance during abnormal condition.

- Good recovery characteristics.

- Good reliability.

The distribution generation has lot of advantages such as load balancing, emergency backup etc. Besides, the advantages it can show negative impact on distribution protection system such as false tripping of protective devices, reduction of reach in distance relays, coordination miss match in protective devices etc. Connecting distributed generation into the power system network may decrease equivalent impedance shown from the point of fault because DG impedance is appear parallel to the existing network and increase level of fault current. Reducing fault current using reactors cause loss of power and voltage drop during healthy condition. Active SFCL is a feasible solution which can show zero impedance during normal condition and high impedance during abnormal condition. With a single phase to ground fault occurs at phase A of distribution system with neutral isolated, the voltage of that phase decrease and induce overvoltage in remaining two phases due to arcing grounds effect. This overvoltage may damage insulation stability of network. Introducing active SFCL can change grounding coefficient which reduce overvoltage amplitude. The effect of SFCL on short circuit current and induced over-voltage reduction when DG's are connected at different locations and at different fault positions are to be studied by designing a simulation model.

\section{THEORETICAL ANALYSIS}

\subsection{Circuit Structure of the ActiveSFCL}

The SFCL consists of air core type transformer and pulse width modulation inverter and its circuit model is shown in Fig-1. The primary winding self-inductance of transformer is represented as $\mathrm{L}_{\mathrm{s} 1}$ and secondary winding self-inductance is represented by $\mathrm{L}_{\mathrm{s} 2}$, PWM inverter filters low harmonic content and does not filter high harmonic content which can be filtered using LC filter. Impedance of the circuit is represented by $Z_{1}$. Load impedance is designed as $Z_{2}$. Mutual inductance is $\mathrm{M}_{\mathrm{S}}$. 


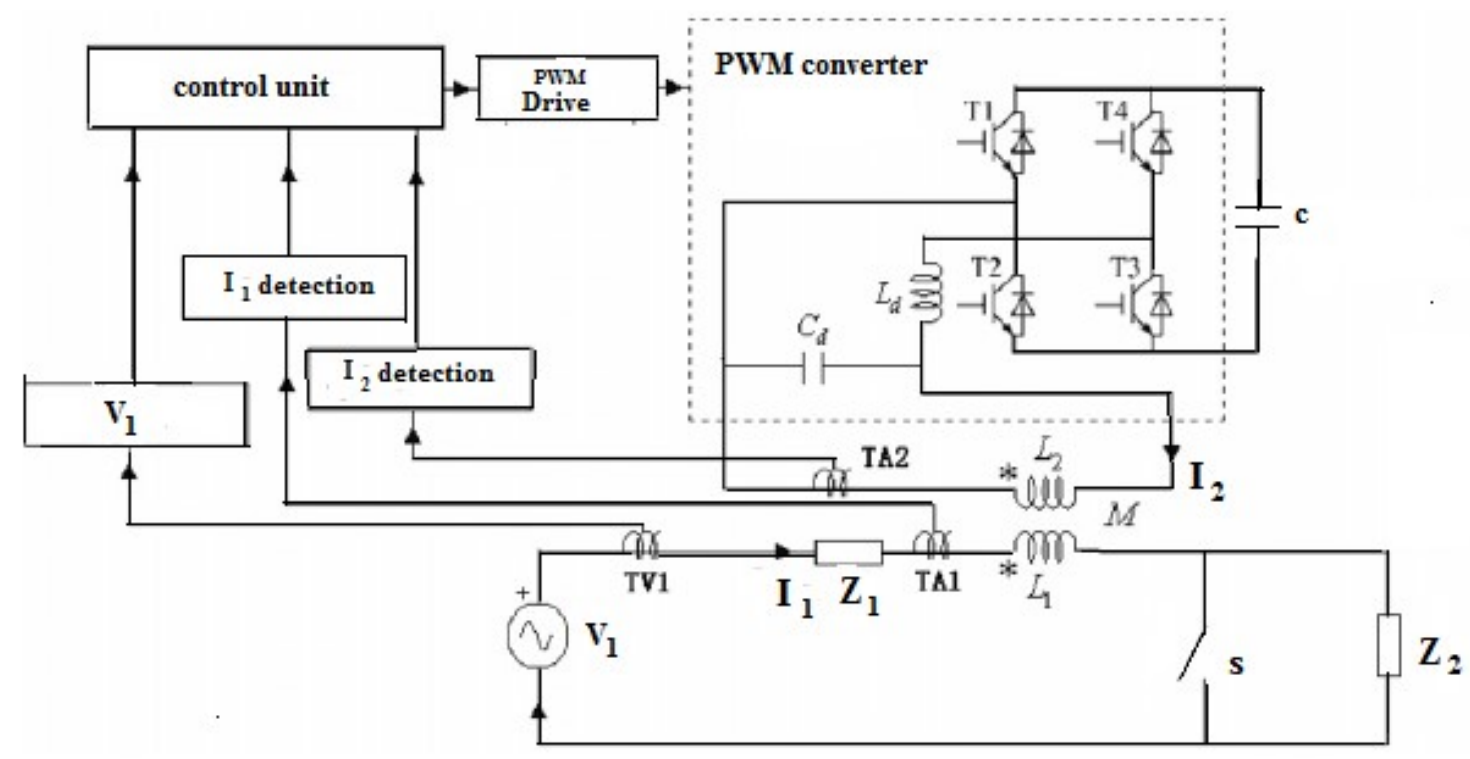

Fig-1: SFCL circuit structure.

Fig-2 indicates equivalent circuit of SFCL. $\mathrm{V}_{\mathrm{s}}$ is the supply voltage and $\mathrm{V}_{\mathrm{p}}$ is the controlled voltage source of converter.

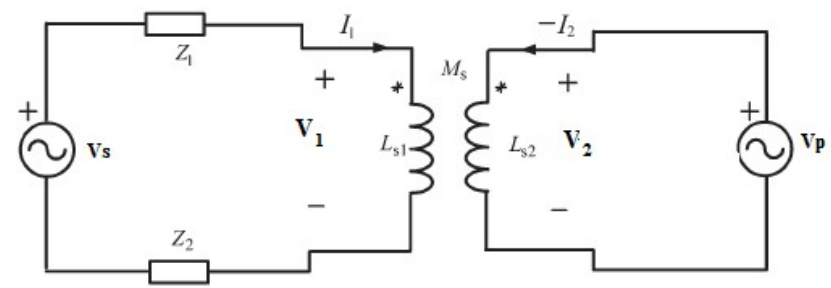

Fig-2: Equivalent circuit of SFCL

The voltage equations of transformer is described by

$$
\left[\begin{array}{l}
V_{1} \\
V_{2}
\end{array}\right]=\left[\begin{array}{cc}
L_{S 1} & M \\
M & L_{S 2}
\end{array}\right]\left[\begin{array}{c}
I_{1} \\
-I_{2}
\end{array}\right]
$$

During normal condition, the $\mathrm{mmf}$ in an air core transformer is regulated to zero by controlling converter output current. So the voltage drop during normal state is zero. When fault condition occurs, the primary voltage of a transformer is controlled by changing converter output current which increase the equivalent impedance of SFCL and suppress the fault current. This can be explained using mathematical equations.

$$
\begin{gathered}
V_{s}=I_{1}\left(Z_{1}+Z_{2}\right)+j \omega L_{s 1} I_{1}-j \omega M I_{2} \\
V_{p}=j \omega M I_{1}-j \omega L_{s 2} I_{2}
\end{gathered}
$$

The term $j \omega L_{s 1} I_{1}-j \omega M I_{2}$ specify voltage acrossprimary winding of transformer which is regulated to zeroby controlling $\mathrm{I}_{2}$ during normal condition. Therefore equivalent impedance of SFCL becomes zero because $Z_{\mathrm{SFCL}}$ $=\mathrm{V}_{1} / \mathrm{I}_{1} \mathrm{I}_{2}$ can be set as,
$\mathrm{I}_{2}=V_{s} \sqrt{\left(\frac{L_{s 1}}{L_{s 2}}\right)} /\left(Z_{1}+Z_{2}\right) K$

Where $\mathrm{K}$ is the coefficient of coupling and its value is $\mathrm{M} / \sqrt{ }\left(L_{s 1} L_{s 2}\right)$.

When fault condition is detected, $Z_{2}$ is shorted and fault current will rise from $I_{1}$ to $I_{f 1}$ and primary voltage will increase to $\mathrm{V}_{\mathrm{fl}}$.

$$
I_{f 1}=\frac{\left(V_{s}+j \omega M I_{2}\right)}{\left(Z_{1}+j \omega L_{s 1}\right)}
$$

$$
V_{f 1}=j \omega L_{s 1} \frac{\left(V_{s}+j \omega M I_{2}\right)}{\left(Z_{1}+j \omega L_{s 1}\right)}-\mathrm{j} \omega M I_{2}
$$

The SFCL impedance can be manage as,

$\mathrm{Z}_{\mathrm{SFCL}}=\mathrm{V}_{\mathrm{fl}} / \mathrm{I}_{\mathrm{fl}}=\mathrm{j} \omega L_{S 1}-\frac{j \omega M I_{2}\left(Z_{1}+j \omega L_{S 1}\right)}{V_{S}+j \omega M I_{1}}$

By controlling $\mathrm{I}_{2}, \mathrm{Z}_{\mathrm{SFCL}}$ impedance can be varied. The transformer primary winding is connected to supply system and secondary terminal is connected to PWM inverter. Here the converter is a voltage source inverter. Air core transformer has linear magnetic characteristics. So, iron losses are absent and magnetic saturation is not present in air core transformer. Size and weight of transformer will decrease.

\subsection{Implementation of SFCL into Power System}

\section{Network}

Active SFCL is connected after generation source and behind the distribution transformer. The radial distribution network consists of six buses. DG's are connected between 2 and 5 buses. 


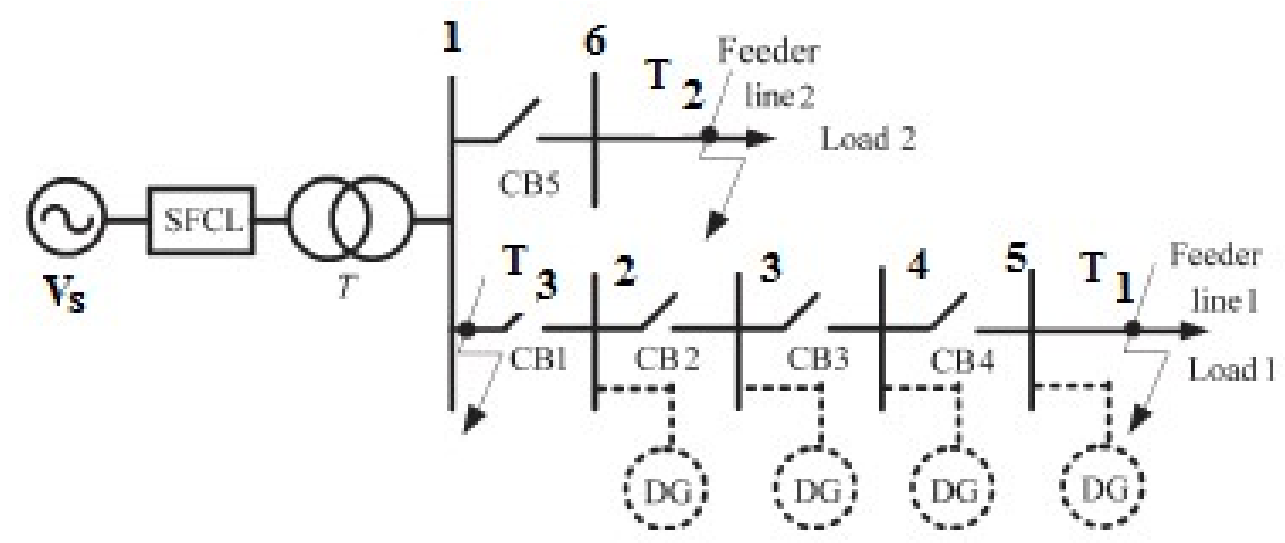

Fig-3: Application of SFCL into distribution network

When a line to ground fault take place on phase $A$ at $T_{1}$ point, SFCL triggered into operation and it reduce the fault current at fault phase. It also reduces overvoltage induced in remaining healthy phases. Overvoltage induced in remaining phases can be calculated using symmetrical component method. Coefficient of grounding in this condition is represented as,

$$
G=-1.5 C /(2+C) \pm j \sqrt{3} / 2
$$

Where $\mathrm{C}$ is the ratio of power system network zero sequence impedance to the positive sequence impedance. By adding SFCL into the network the positive sequence reactance increased and the ratio $\mathrm{C}$ decreased which decreases $\mathrm{G}$ value and corresponding overvoltage in the remaining two phases. The overvoltage in healthy two phases can be expressed as

$\mathrm{V}_{\mathrm{BN}}=\mathrm{V}_{\mathrm{CN}}=1.732\left|\frac{\sqrt{\left(\left(G+\frac{1}{2}\right)^{2}+\frac{3}{4}\right)}}{G+1}\right| \mathrm{V}_{\mathrm{AN}}$

Where $\mathrm{V}_{\mathrm{AN}}$ is the phase to ground voltage (RMS value) under normal operating condition.

\section{FAULT CURRENT DETECTION}

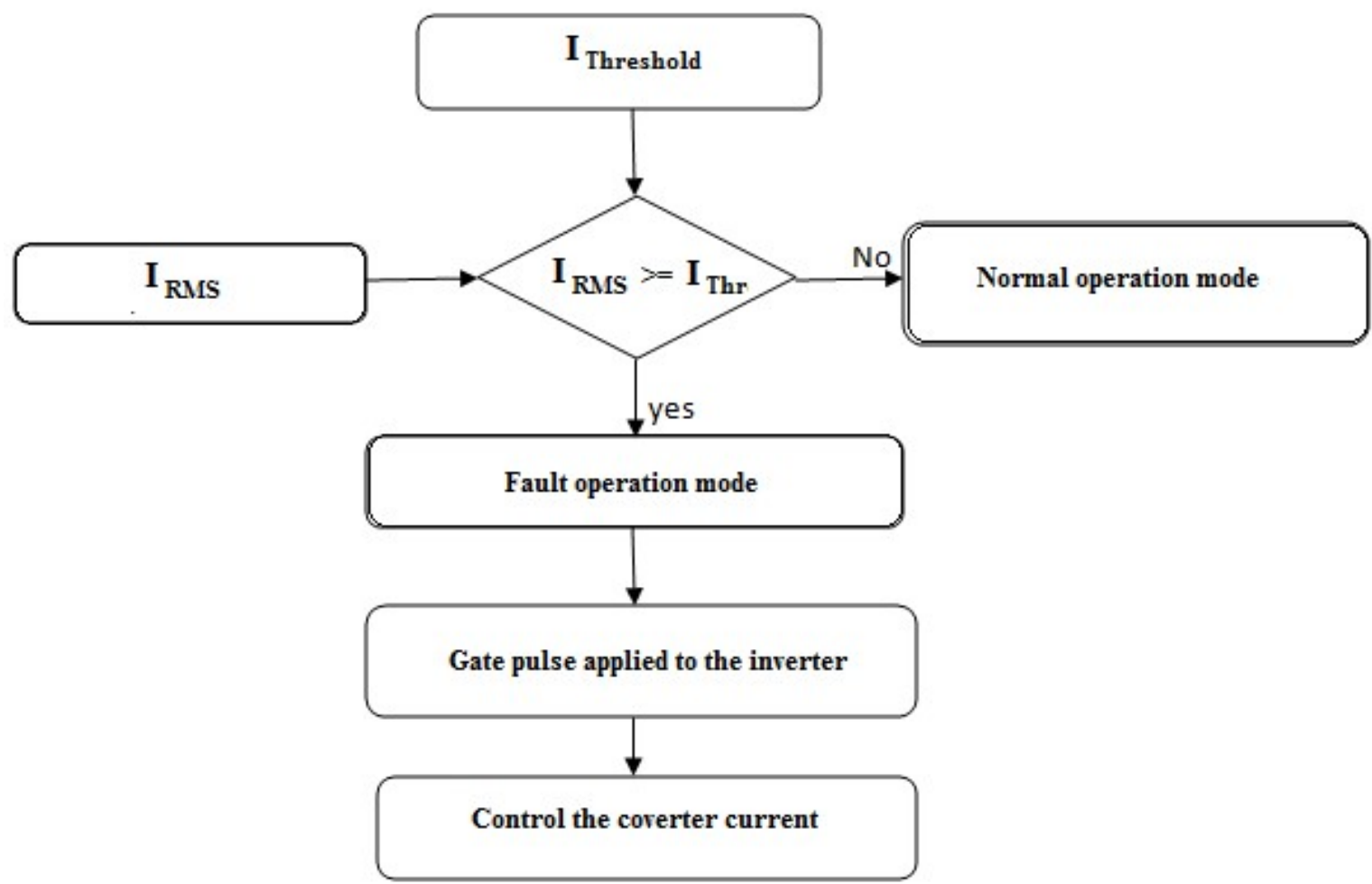

Fig-4: Control strategy for fault current detection

Control unit compares threshold value with RMS current value. If RMS value is greater than threshold value it specifies fault condition. During this period gate pulses are applied to the inverter which changes the converter output current. In normal operation mode RMS current is less than threshold value so the gate pulses are not applied to the inverter. 


\section{SIMULATION MODEL}

\subsection{SFCL Model}

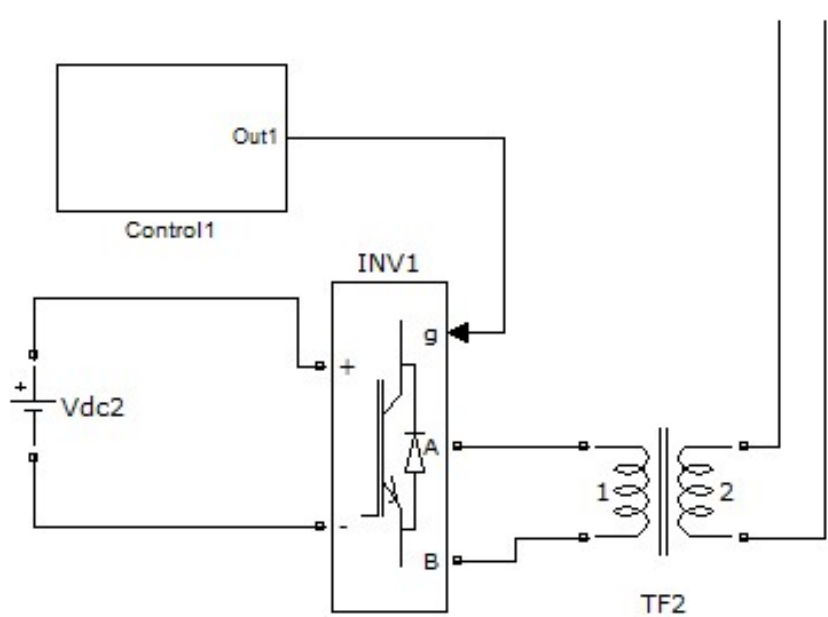

SFCL consists of a voltage source inverter, control circuit, single phase transformer. The control output from voltage source inverter is applied to secondary winding of air core super conducting transformer and its primary winding is connected to distribution line.

\subsection{Control unit of SFCL model}

It consists of switch, relational operator, PWM generator. Switch block compares rms signal with threshold signal. If the condition specify in the relation operator is true then signal connected to first terminal of switch is supplied to output port else third terminal signal is supplied to the output port. Here the first terminal signal is gate pulse produced by PWM generator and second terminal is zero.

Fig-5: SFCL simulink model

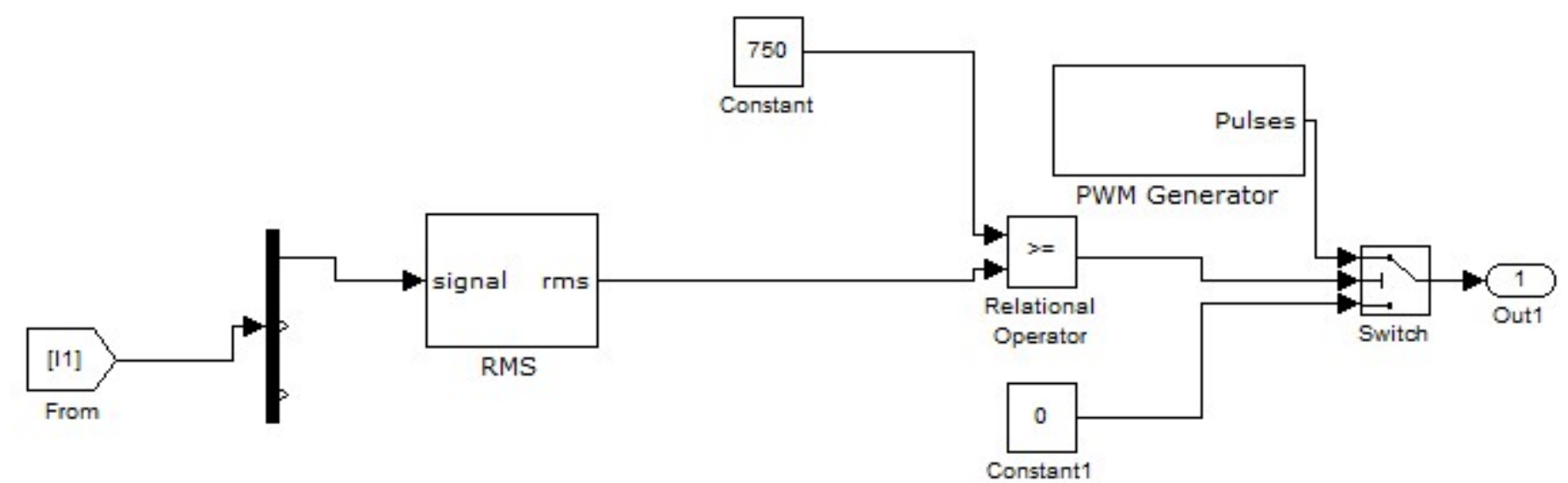

Fig-6: Simulink model of control unit

Table-1: Parameters used in the simulation model

\begin{tabular}{|c|c|}
\hline \multicolumn{2}{|c|}{ SFCL } \\
\hline Self-inductance $\left(\mathrm{L}_{\mathrm{s} 1}\right)$ & $45 \mathrm{mH}$ \\
\hline Self-inductance $\left(\mathrm{L}_{\mathrm{s} 2}\right)$ & $35 \mathrm{mH}$ \\
\hline Mutual inductance $\left(\mathrm{M}_{\mathrm{s}}\right)$ & $33 \mathrm{mH}$ \\
\hline
\end{tabular}

\begin{tabular}{|c|c|}
\hline \multicolumn{2}{|c|}{ Transformer } \\
\hline Capacity & $6000 \mathrm{kVA}$ \\
\hline Transformation ratio & $33 \mathrm{KV} / 11 \mathrm{KV}$ \\
\hline
\end{tabular}

\begin{tabular}{|c|c|}
\hline \multicolumn{2}{|c|}{ Feeder line } \\
\hline Line length & $\begin{array}{c}\mathrm{L}_{\mathrm{AF}}=\mathrm{L}_{\mathrm{AB}}=\mathrm{L}_{\mathrm{BC}}=4 \mathrm{~km} \\
\mathrm{~L}_{\mathrm{CD}}=10 \mathrm{~km}, \mathrm{~L}_{\mathrm{DE}}=15 \mathrm{~km}\end{array}$ \\
\hline Line parameter & $(0.3+\mathrm{j} 0.1) \Omega / \mathrm{km}$ \\
\hline
\end{tabular}

\begin{tabular}{|c|c|}
\hline \multicolumn{2}{|c|}{ Load } \\
\hline First load & $75 \Omega$ \\
\hline Second load & $(15+\mathrm{j} 15) \Omega$ \\
\hline
\end{tabular}




\subsection{Overvoltage and Fault Current Suppressing Characteristics of the SFCL}

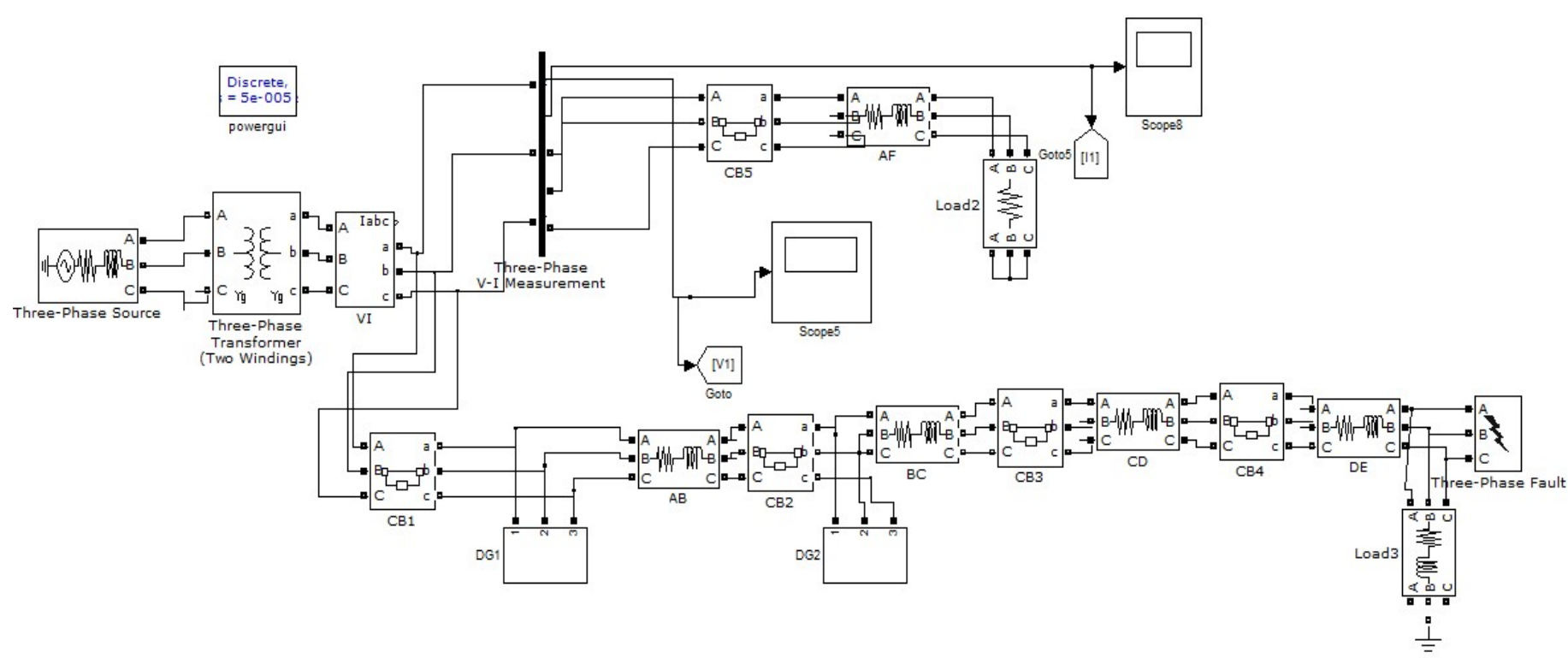

Fig-7:Simulation model of distribution network without SFCL

Fig-7 shows simulation model of distribution network without SFCL and a single phase fault at $\mathrm{T}_{1}$ point. When a single phase fault is at phase $A$ then the current of that phase and voltage of remaining two phases are increased which are shown in Fig-10 and Fig-9 respectively.

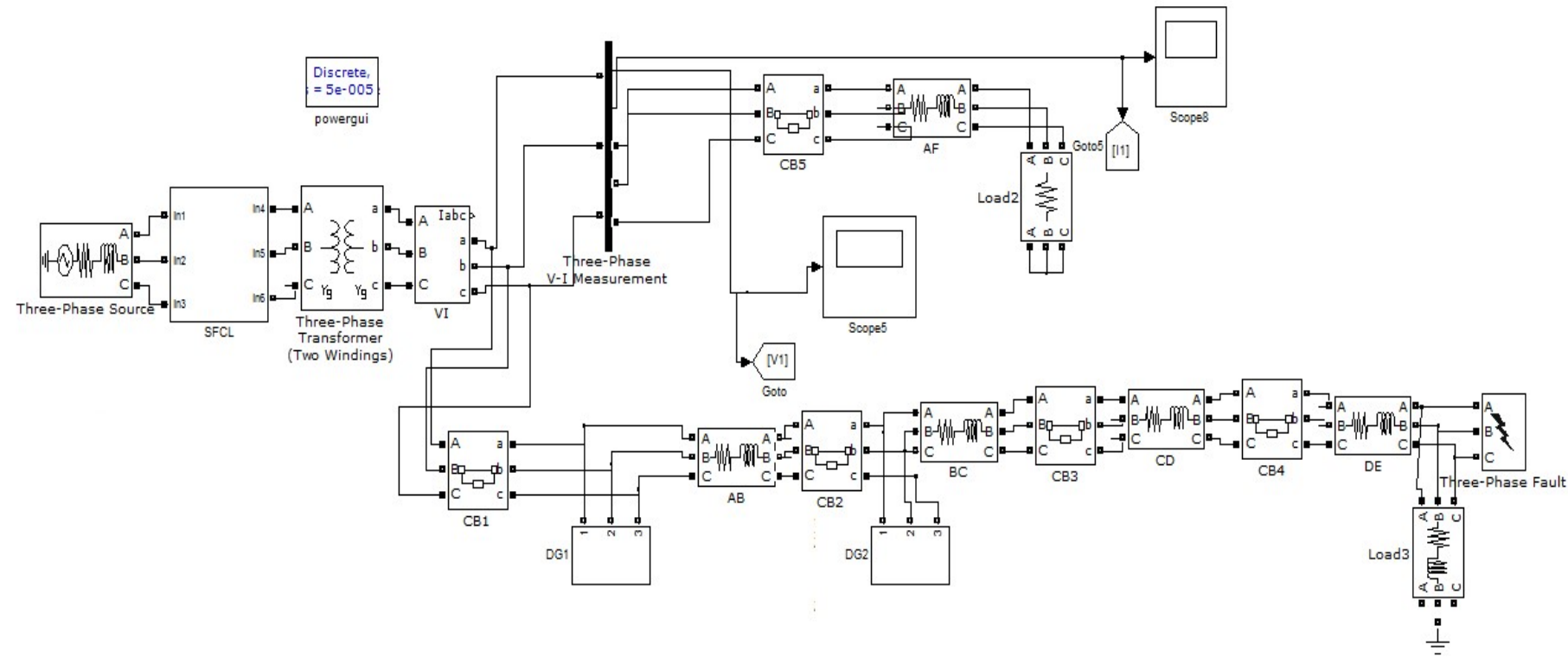

Fig-8: Simulation model of distribution network with SFCL

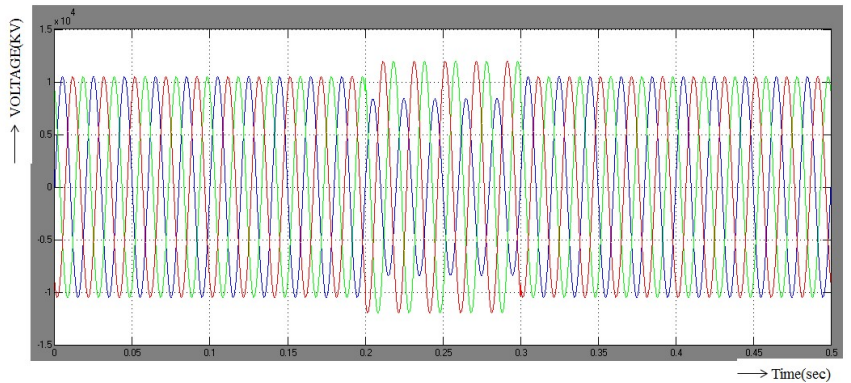

Fig-9: Voltage waveform of distribution network without SFCL

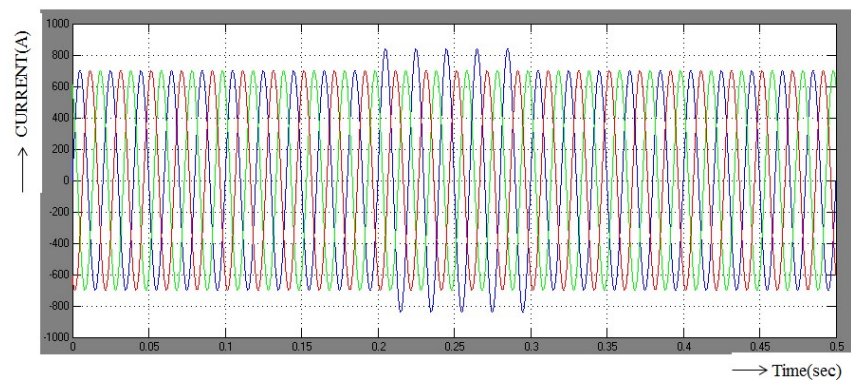

Fig-10: Current waveform of distribution network without SFCL 
Fig-8 shows simulation model of distribution network with SFCL. SFCL increase impedance during fault condition and reduce short circuit current at faulty phase and reduce over voltage in healthy phases which are shown in Fig-11 and Fig-12 respectively.

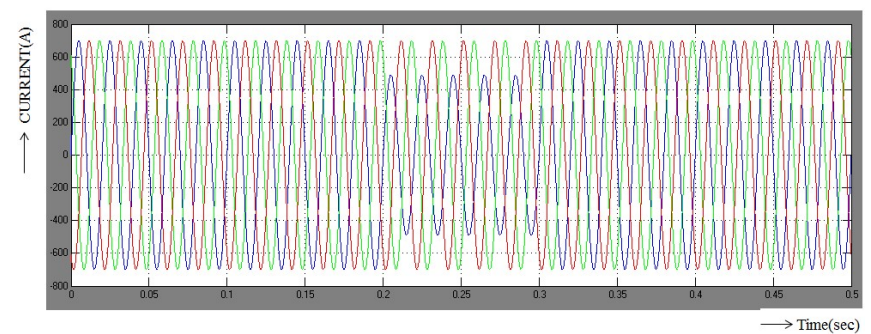

Fig-11: Current waveform of distribution network with SFCL

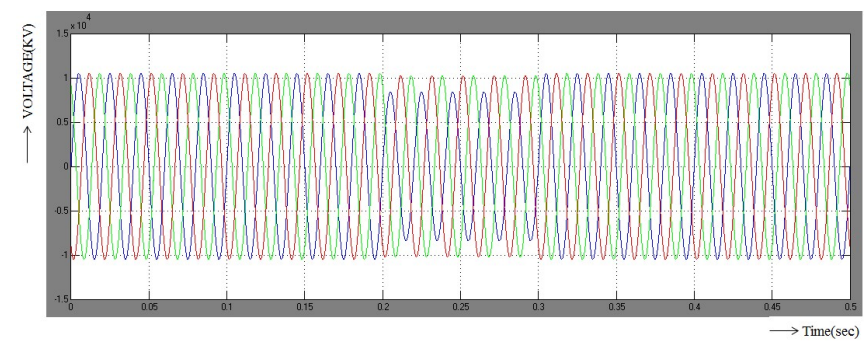

Fig-12: Voltage waveform of distribution network with SFCL

When a three phase fault occurs at T1 point corresponding current waveform is shown in Fig-13.

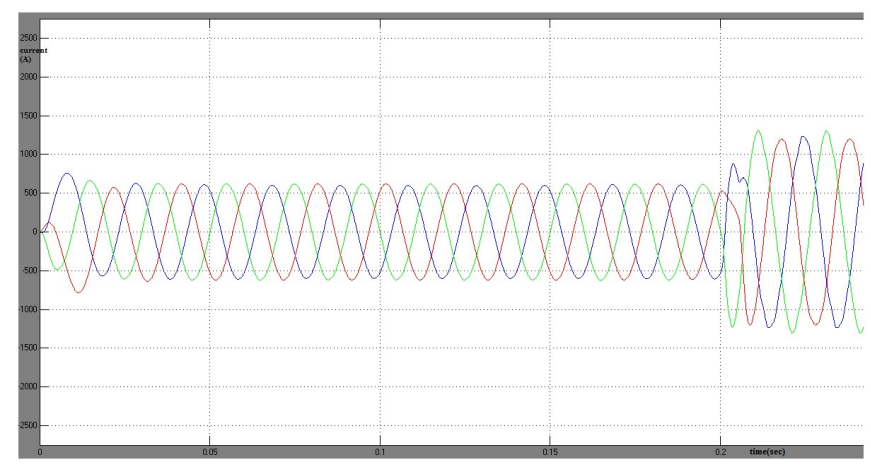

Fig-13: Current waveform of distribution network with SFCL.

Current suppression characteristics can be analyzed by interconnecting without SFCL network and with SFCL network. Corresponding current waveform is shown in Fig14.

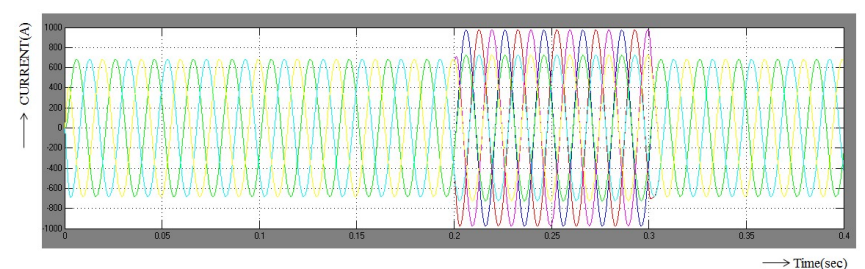

Fig-14: Comparison of current waveforms of inter connected distribution network with SFCL and without SFCL.

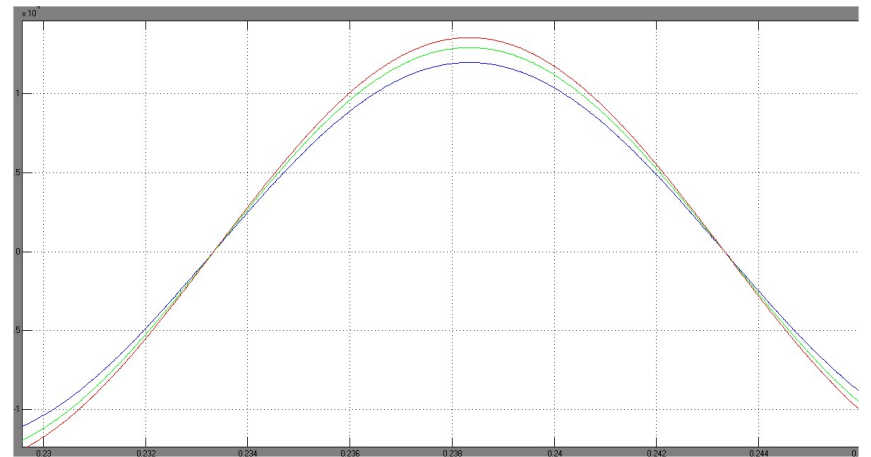

Fig-15: Voltage waveform when DG is at different positions without SFCL.

Suppose that each DG is supplying $100 \%$ capacity of connected load, and the fault is located at $T_{1}$ point (phase- $A$ is shorted), and the fault start time is $t=0.2 \mathrm{~s}$, the Simulation is done when the DG1 is connected at fixed position at Bus 2, and DG2 is connected at different positions of Buses 3, 4, and 5.Fig-15shows voltage waveform of helathy phases when falut is at phase A and DG's are connected at different positions without SFCL. As SFCL is connected the voltage magnitude decrease which is shown in Fig-16.

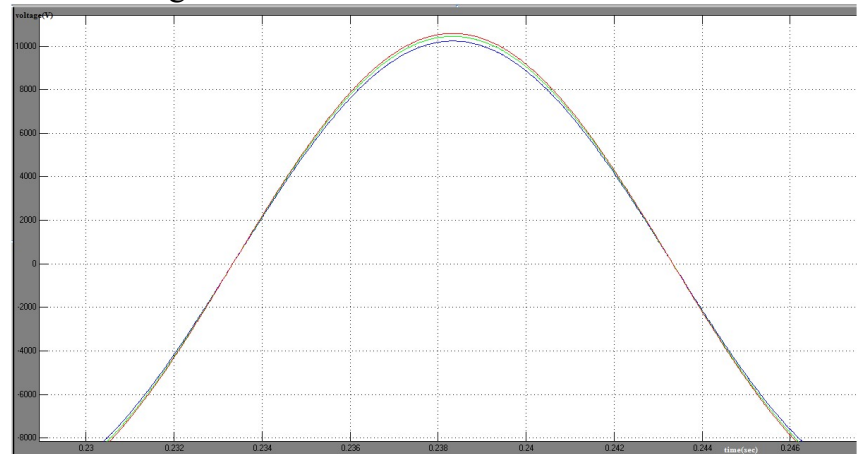

Fig-16: Voltage waveform when DG is at different positions with SFCL.

Table-2: Overvoltage suppressing characteristics when DG's are at different location.

\begin{tabular}{|c|c|c|}
\hline $\begin{array}{c}\text { Location of } \\
\text { DG's }\end{array}$ & $\begin{array}{c}\text { DG-1 at Bus-2 and } \\
\text { DG-2 at Bus-4 }\end{array}$ & $\begin{array}{c}\text { DG-1 at Bus-2 and } \\
\text { DG-2 at Bus-5 }\end{array}$ \\
\hline $\begin{array}{c}\text { \% Voltage } \\
\text { suppression }\end{array}$ & 24 & 17.25 \\
\hline
\end{tabular}

Table-2 shows overvoltage suppressing characteristics of SFCL when DG's are at different location and a single line to ground fault occurs at T1 point.

Table-3: Fault current suppressing characteristics when fault is at different location.

\begin{tabular}{|c|c|c|}
\hline Fault location & $\mathrm{T}_{1}$ point & $\mathrm{T}_{2}$ point \\
\hline $\begin{array}{l}\text { \% current } \\
\text { reduction }\end{array}$ & 8.62 & 27.18 \\
\hline
\end{tabular}

Table-3 shows fault current suppressing characteristics of SFCL when three phase fault taken place at different locations. 


\section{CONCLUSION}

The performance of SFCL on short circuit current reduction and overvoltage suppression in distribution system with multiple DG's connected is examined. SFCL minimize the overvoltage magnitude induced in the healthy phases during single phase to ground fault and protect the distribution system equipment. SFCL can also reduce the short circuit current induced during three phase fault and improves the reliability and safety of the power system. SFCL can show better limiting performance as the distance between fault position and SFCL location is less.

\section{REFERENCE}

[1] T. Janowski, S. Kozak, B. Kondratowicz-Kucewicz, G. Wojtasiewicz, and J. Kozak, "Analysis of transformer type superconducting fault current limiters," IEEE Trans. Appl. Supercond., vol. 17, no. 2, pp. 1788-1790, Jun. 2007.

[2] S.-Y. Kim and J.-O. Kim, "Reliability evaluation of distribution network with DG considering the reliability of protective devices affected by SFCL, "IEEE Trans. Appl. Supercond., vol. 21, no. 5, pp. 3561-3569, Oct. 2011.

[3] M. Song, Y. Tang, N. Chen, Z. Li, and Y. Zhou, "Theoretical analysis and experiment research of high temperature superconducting air core transformer," in Proc. Int. Conf. Electr. Mach. Syst., Wuhan, China, vol. 13, pp. 4394-4397, Oct. 2008.

[4] H. Yamaguchi and T. Kataoka, "Stability analysis of air-core superconducting power transformer," IEEE Trans. Appl. Supercond., vol. 7, no. 2, pp. 1013-1016, Jun. 1997.

[5] L. Chen, Y. J. Tang, J. Shi, N. Chen, M. Song, S. J. Cheng, Y. Hu, and X. S. Chen, "Influence of a voltage compensation type active superconducting fault current limiter on the transient stability of power system," Phys. C, vol. 46, no. 15, pp. 1760-1764, Oct. 2009.

\section{BIOGRAPHIES}

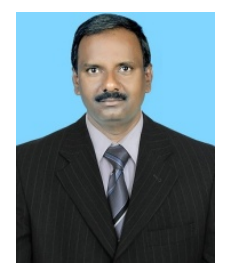

P. Umapathi Reddy received B.E from Andhra university, M. Tech (EPS) from JNTUA and Ph.D. degree from JNTUK in 1998, 2004 and 2013 respectively. Currently he is a professor at Sree Vidyanikethan Engineering College, Tirupati. His research interest includes power distribution systems and power system operation and control. He is a life member of Indian society for technical education.17 international journals, 13 international and national conferences in his credit.

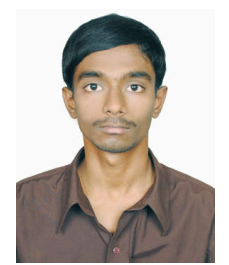

M. Anand Kumar received the B. Tech degree in electrical and electronics engineering from NBKRIST in 2013. He is pursuing $M$. Tech degree in electrical power systems at Sree Vidyanikethan Eng. College. 